Rapid Reviews COVID-19

\title{
Reviews of "Assessment of physiological signs associated with COVID-19 measured using wearable devices"
}

Chi Hwan Lee ${ }^{1}$, Yehuda Weizman ${ }^{2}$

${ }^{1}$ Purdue University, Biomedical Engineering, United States,

${ }^{2}$ Swinburne University of Technology - Hawthorn Campus: Swinburne University of Technology, Faculty of Science, Engineering and Technology, Australia

Published on: Nov 07, 2020

DOI: $10.1162 / 2$ e3983f5.9af8845f

License: Creative Commons Attribution 4.0 International License(CC-BY 4.0) 
To read the original manuscript, click the link above.

Summary of Reviews: This study leverages wearable device technology to track biometrics in COVID19-afflicted individuals and develop models that predict both illness and risk of hospitalization. These results should be considered reliable.

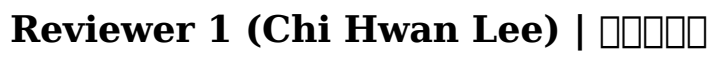

Reviewer 2 (Yehuda Weizman)

$$
\begin{aligned}
& \text { RR:C19 Strength of Evidence Scale Key. }
\end{aligned}
$$

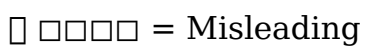

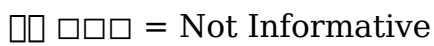

$$
\begin{aligned}
& \text { प्रा पि = Potentially Informative }
\end{aligned}
$$

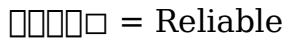

$$
\begin{aligned}
& \text { प्राप्र = Strong }
\end{aligned}
$$

To read the reviews, click the links below. 